$06.4 ; 06.5 ; 13.3$

\title{
Плазмохимический способ модификации карбида кремния для получения частиц с управляемой морфологией поверхности
}

\author{
(C) Т.А. Шалыгина ${ }^{1,2}$, М.С. Руденко ${ }^{1}$, И.В. Немцев ${ }^{2-4}$, В.А. Парфенов ${ }^{5}$, С.Ю. Воронина ${ }^{1}$ \\ ${ }^{1}$ Сибирский государственный университет науки и технологий им. акад. М.Ф. Решетнёва, \\ Красноярск, Россия \\ ${ }^{2}$ Сибирский федеральный университет, Красноярск, Россия \\ ${ }^{3}$ Федеральный исследовательский центр „Красноярский научный центр СО РАН“, \\ Красноярск, Россия \\ ${ }^{4}$ Институт физики им. Л.В. Киренского СО РАН, ФИЦ КНЦ СО РАН, Красноярск, Россия \\ ${ }^{5}$ Институт химии и химической технологии СО РАН, ФИЦ КНЦ СО РАН, \\ Красноярск, Россия \\ E-mail: leonova.ta@inbox.ru
}

Поступило в Редакцию 1 октября 2021 г.

В окончательной редакции 2 ноября 2021 г.

Принято к публикации 8 ноября 2021г.

\begin{abstract}
Представлен плазмохимический способ модификации частиц карбида кремния, позволяющий получить частицы с управляемой морфологией поверхности. Изменяющимся параметром обработки частиц являлось соотношение объемных долей плазмообразующего (Ar) и дополнительного $(\mathrm{H})$ газов. Показано, что при соотношении $\mathrm{Ar} / \mathrm{H}=100 / 0$ наблюдается образование углеродной оболочки, при соотношениях $\mathrm{Ar} / \mathrm{H}$, равных 91/9 и 84/16, частицы характеризуются углеродной оболочкой, декорированной кремниевыми наночастицами или нитевидными нанокристаллами соответственно. Модифицированные частицы проанализированы с помощью сканирующей электронной микроскопии и спектроскопии комбинационного рассеяния.
\end{abstract}

Ключевые слова: карбид кремния, плазмохимия, морфология поверхности, наночастицы, нитевидные нанокристаллы, углеродная оболочка, ядро-оболочка.

DOI: 10.21883/PJTF.2022.04.52078.19042

Карбид кремния (SiC) обладает уникальным набором физико-химических свойств, включая низкую плотность, высокую твердость и прочность, химическую стойкость в окислительных средах и термостойкость [1]. $\mathrm{SiC}$ все чаще рассматривают в качестве дисперсного наполнителя для полимерных композиционных материалов (ПКМ) [2]. Благодаря наполнению полимерной матрицы частицами $\mathrm{SiC}$ происходит заметное увеличение теплопроводности [3], модуля упругости [4], теплостойкости и др. Кроме того, авторы работы [5] изготовили композит на основе поливинилового спирта и полиакриловой кислоты с наночастицами $\mathrm{SiC}$, проявляющий эффект памяти формы. Уникальность добавления частиц $\mathrm{SiC}$ заключалась в появлении возможности инициирования эффекта памяти формы бесконтактным способом, а именно под действием микроволнового излучения.

При разработке дисперсно-наполненных ПКМ с новыми функциональными свойствами необходимо обеспечить и высокие физико-механические характеристики, которые во многом зависят от межфазного взаимодействия полимера с поверхностью наполнителя. Для улучшения межфазного взаимодействия применяются различные методы функционализации поверхности наполнителя [6]. Как известно, $\mathrm{SiC}$ химически инертен и проведение химической модификации его поверхности сильно ограничено. Авторы работы [7] опубликовали результаты компьютерного моделирования структуры дисперсно-наполненных полимерных композитов, которые показали, что наряду с каким-либо взаимодействием полимерных цепей с поверхностью дисперсного наполнителя важно учитывать и морфологию (рельеф) этой поверхности. Они нашли, что плотность полимера в граничных слоях и количество свободного объема в межфазной области сильно различаются в зависимости от того, имеет ли частица гладкую поверхность или щетинообразный рельеф. Таким образом, путем изменения морфологии поверхности частиц наполнителя появляется возможность управления конечными свойствами ПКМ.

В настоящей работе предложен способ плазмохимической модификации частиц карбида кремния, позволяющий получить частицы с управляемой морфологией поверхности. В качестве объектов исследования выступали частицы $\mathrm{SiC}$ (фракция F800), характеризующиеся размером частиц от 6 до $8 \mu \mathrm{m}$ согласно ГОСТ 26327-84 (СТ СЭВ 4169-83).

Модификация частиц осуществлялась с помощью плазмотрона F4 комплекса плазменного напыления. Между вольфрамовым катодом и медным водоохлаждаемым анодом (соплом) возбуждалась электрическая дуга, нагревающая рабочий газ, в результате чего он истекал из сопла в виде плазменной струи. Порошок $\mathrm{SiC}$ подавался в плазменную струю потоком транспортирующего газа $\left(Q_{\mathrm{Ar}}=5 \mathrm{l} / \mathrm{min}\right)$ по специальному ин- 


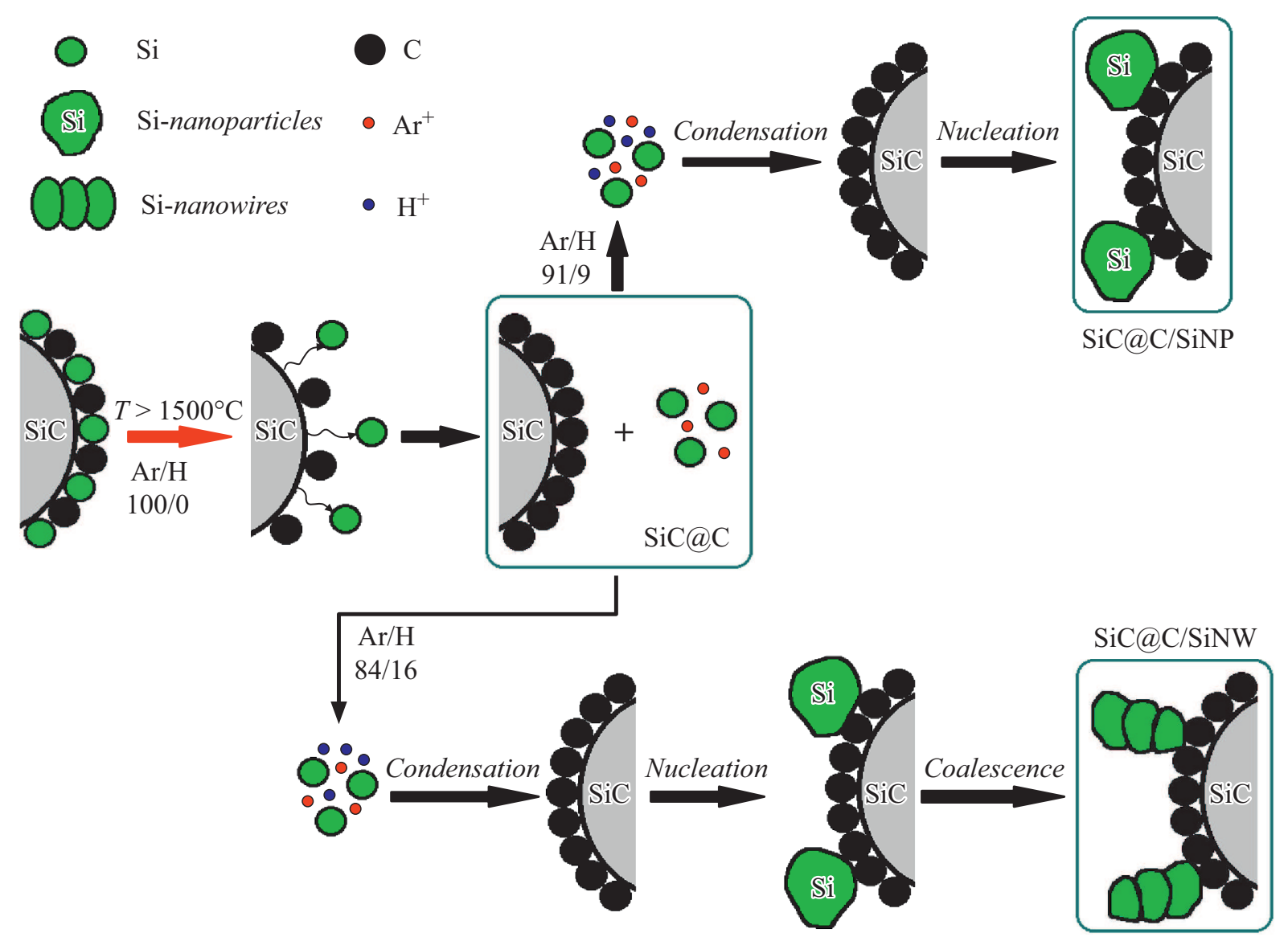

Рис. 1. Схематическое изображение процессов, протекающих в плазмохимическом реакторе при модификации частиц $\mathrm{SiC}$ (цветной вариант рисунка представлен в электронной версии статьи).

жектору, расположенному на срезе сопла. Мощность дуги определялась силой тока $(500 \mathrm{~A})$ и напряжением, которое в свою очередь определялось видом и расходом плазмообразующего газа $\left(Q_{\mathrm{Ar}}=301 / \mathrm{min}\right)$.

В качестве изменяющегося параметра при плазмохимической модификации было выбрано соотношение объемных долей плазмообразующего (аргона) и дополнительного (водорода) газов $(\mathrm{Ar} / \mathrm{H})$, которые подавались через осевое отверстие вольфрамового электрода. Порошок $\mathrm{SiC}$ подавался с помощью устройства подачи пробы с транспортирующим газом (Ar) на срез плазменной струи, сгенерированной плазмотроном. Проходя через область плазмы, порошок нагревался и с потоком плазмообразующего и дополнительного газов $(\mathrm{Ar} / \mathrm{H})$ попадал в реактор, где конденсировался на водоохлаждаемых стенках реактора в виде дисперсного порошка.

Поскольку водород обладает значительно большей теплопроводностью (в 10 раз), добавление его в плазмохимический реактор способствует ускорению протекающих в нем процессов. Основным процессом, который протекает даже в отсутствие водорода в реакторе $(\mathrm{Ar} / \mathrm{H}=100 / 0)$, при этом является сублимация атомов кремния с поверхности частиц $\mathrm{SiC}$. Этот процесс можно описать следующим образом.
Попадая в горячую область плазменного потока, поверхность частицы $\mathrm{SiC}$ нагревается до температуры свыше $1500^{\circ} \mathrm{C}$, происходит разрыв связи, в которой участвует атом кремния в плоскости (0001) с ненасыщенной валентностью. Он испаряется и формирует область разрыва верхнего слоя (лунку) [8]. В то же время атом углерода стремится к образованию связи с одним из ближайших углеродных атомов. В области разрушения верхнего слоя $\mathrm{SiC}$ (лунки) постепенно формируется единственный компактный кластер (островок) из нескольких графеновых ячеек. Этот процесс продолжается до тех пор, пока частица не попадет в холодную область плазменного потока и ее поверхность не остынет.

При добавлении до 9vol.\% водорода в реактор $(\mathrm{Ar} / \mathrm{H}=91 / 9)$ эти процессы ускоряются и сублимирующиеся атомы кремния, находящиеся все еще в горячей области плазмы, конденсируются на более „холодной“ углеродной оболочке ближайшей частицы. Далее происходит процесс нуклеации и рост кремниевых наноструктур, причем их размер зависит от времени нахождения частиц в высокотемпературной области плазмы. Увеличение времени нахождения частиц в данной области происходит за счет добавления водорода в реактор 

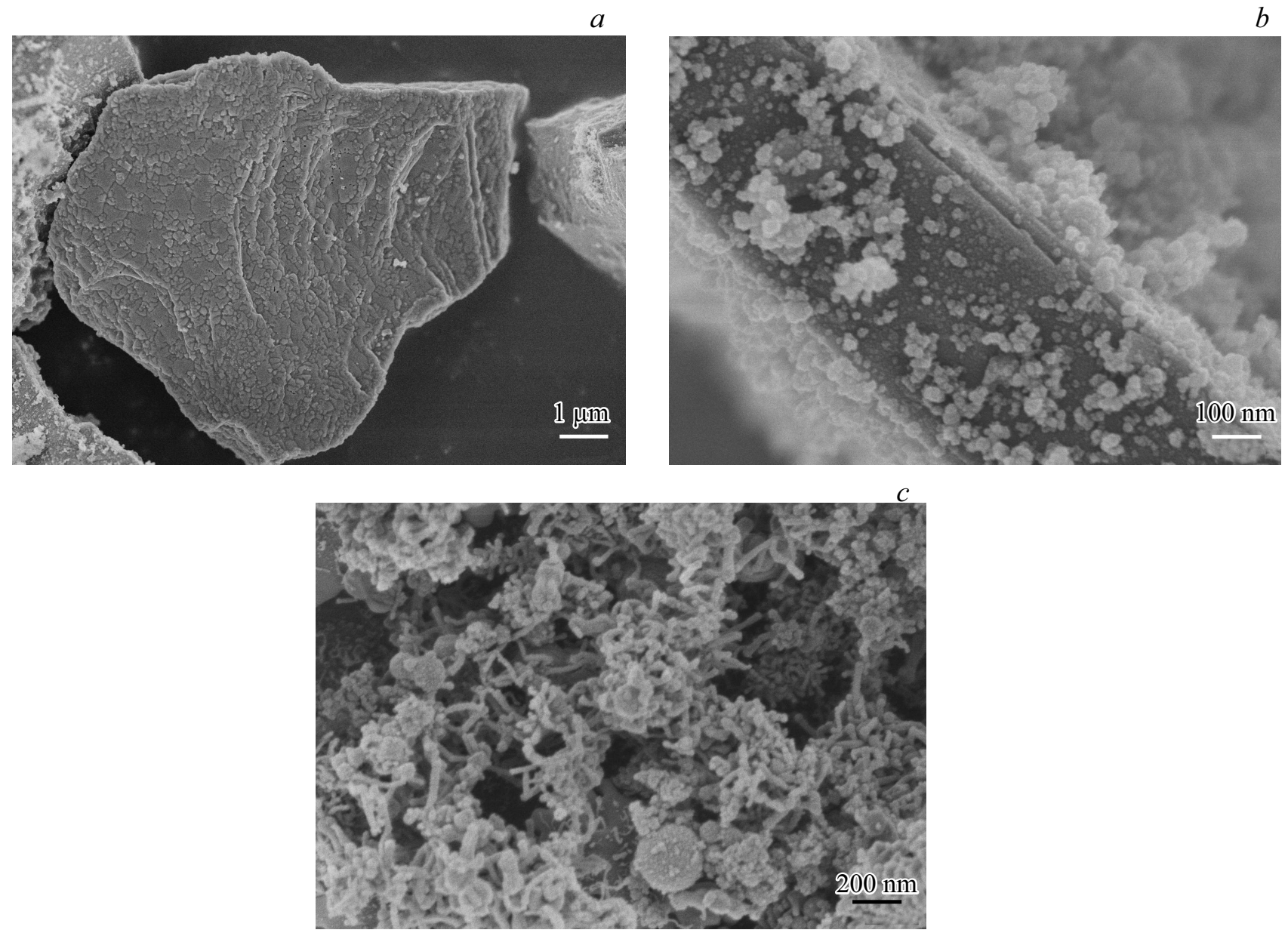

Рис. 2. СЭМ-изображения модифицированных частиц $\mathrm{SiC}$ при различном соотношении плазмообразующего и дополнительного газов $\mathrm{Ar} / \mathrm{H}: a-100 / 0, b-91 / 9, c-84 / 16$.

до 16 vol.\% ( $\mathrm{Ar} / \mathrm{H}=84 / 16)$. Непрерывное поступление атомов $\mathrm{Si}$ к зародышам порождает дальнейший их рост в 1D-структуры (рис. 1). Добавление водорода свыше 16 vol.\% приводит к обратному процессу - сублимации атомов кремния с поверхности уже сформировавшихся кремниевых нитевидных нанокристаллов (ННК). По этой причине частицы $\mathrm{SiC}$, модифицированные при соотношении $\mathrm{Ar} / \mathrm{H}$, равном 77/23 и 72/28, далее рассматриваться не будут.

Визуализация морфологических особенностей порошка осуществлялась с использованием сканирующего электронного микроскопа (СЭМ) высокого разрешения FE-SEM S-5500 (Hitachi Ltd., Tokyo, Japan) при ускоряющем напряжении $3 \mathrm{kV}$ и токе пучка $20 \mathrm{nA}$. На микрофотографиях образцов, полученных при соотношениях $\mathrm{Ar} / \mathrm{H}=91 / 9$ и 84/16, видны сформировавшиеся на поверхности модифицированных частиц $\mathrm{SiC}$ наноструктуры в виде наночастиц или ННК соответственно (рис. 2). При этом диаметр наночастиц составляет от 30 до $60 \mathrm{~nm}$, ННК характеризуются диаметром около $50 \mathrm{~nm}$ и длиной около $300-400 \mathrm{~nm}$.

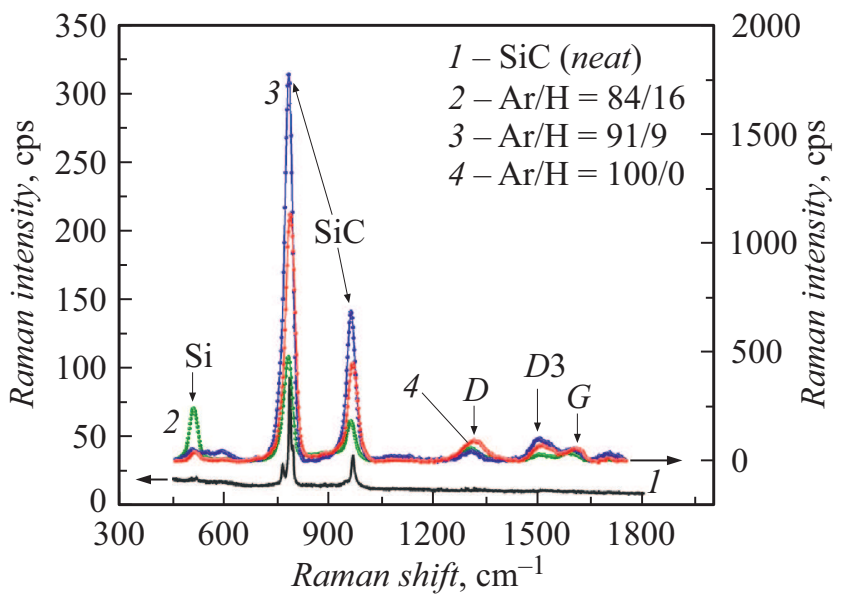

Рис. 3. Спектры комбинационного рассеяния модифицированных частиц $\mathrm{SiC}$.

На рис. 3 представлены спектры комбинационного рассеяния, полученные при комнатной температуре с помощью спектрометра Bruker RFS 100/S. В качестве ис- 
Значения насыпной плотности порошков и удельной площади поверхности частиц $\mathrm{SiC}$

\begin{tabular}{c|c|c|c|c}
\hline \multirow{2}{*}{ Параметр } & \multicolumn{4}{|c}{ Образец } \\
\cline { 2 - 5 } & $\mathrm{SiC}$ & $\begin{array}{c}\mathrm{SiC} \text { при } \\
\mathrm{Ar} / \mathrm{H}=100 / 0\end{array}$ & $\begin{array}{c}\mathrm{SiC} \text { при } \\
\mathrm{Ar} / \mathrm{H}=91 / 9\end{array}$ & $\begin{array}{c}\mathrm{SiC} \text { при } \\
\mathrm{Ar} / \mathrm{H}=84 / 16\end{array}$ \\
\hline Насыпная плотность $\rho_{p}, \mathrm{~g} / \mathrm{cm}^{3}$ & 1.261 & 0.682 & 0.589 & 0.479 \\
Удельная площадь поверхности & 3 & 15 & 38.8 & 45 \\
$S_{\text {Вет, } \mathrm{m}^{2} / \mathrm{g}}$ & & & &
\end{tabular}

точника света для возбуждения рамановского рассеяния применялся непрерывный Nd:YAG-лазер с возбуждающей линией $1.064 \mu \mathrm{m}$. Спектры были записаны в диапазоне 2-1800 $\mathrm{cm}^{-1}$ (рабочее спектральное разрешение $\left.2 \mathrm{~cm}^{-1}\right)$. В спектре исходных микрочастиц $\mathrm{SiC}$ присутствуют основные моды поперечных акустических и оптических ветвей, характеризующих структуру политипа $6 H$-SiC. После обработки микрочастиц основные пики сохраняются, однако можно заметить появление пиков $D$ и $G$ при 1320 и $1600 \mathrm{~cm}^{-1}$, которые обусловлены присутствием упорядоченного углерода, при этом наличие дополнительного пика ,дефектов“" $D 3\left(\sim 1510 \mathrm{~cm}^{-1}\right)$ может указывать на наличие в молекулярной структуре внутрислоевых и межслоевых дефектов. Кроме того, у образцов, полученных при соотношениях $\mathrm{Ar} / \mathrm{H}=91 / 9$ и 84/16, можно заметить появление интенсивного пика при $508 \mathrm{~cm}^{-1}$, который относится к колебанию Siфононов, находящихся на границе раздела поверхности $\mathrm{Si}-$ нанокристалла и оксидного слоя $\mathrm{SiO}_{2}$ [9].

Насыпная плотность $\left(\rho_{p}\right)$ порошков модифицированных частиц $\mathrm{SiC}$ определялась согласно ГОСТ 19440-94. Из таблицы видно, что при увеличении содержания водорода в плазмохимическом реакторе значения насыпной плотности образцов существенно снижаются. Так, при соотношении $\mathrm{Ar} / \mathrm{H}=84 / 16 \rho_{p}$ уменьшилась более чем в 2.5 раза по сравнению с $\rho_{p}$ немодифицированных частиц $\mathrm{SiC}$.

Измерение текстурных параметров образцов исследуемых материалов выполнено с помощью ASAP-2420 (Micromeritics, USA). Предварительно материалы были подвергнуты дегазации поверхности при температуре $250^{\circ} \mathrm{C}$ в течение $8 \mathrm{~h}$ при давлении не более $20 \mu \mathrm{m}$ ртутного столба. Затем материал известной массы был подвергнут газоадсорбционному измерению при температуре $77 \mathrm{~K}$ с регистрацией изотермы адсорбции в диапазоне относительных давлений $P / P_{0}=0.005-0.995$. Подача аналитического газа (азота) осуществлялась в режиме дозирования малых порций. Обработка результатов измерений осуществлялась с помощью моделей ВЕТ (Брунауэра-Эммета-Теллера), ВЈН (Баррета-Джойнера-Халенды), $t$-plot ( $t$-метод де Бура) и $\alpha$-S. Результаты показали увеличение значения удельной площади поверхности $\left(S_{\mathrm{BET}}\right)$ с увеличением содержания водорода в реакторе. Максимальным значением $S_{\text {Вет }}$ обладают частицы $\mathrm{SiC}$ при $\mathrm{Ar} / \mathrm{H}=84 / 16$, оно в 15 раз больше значения $S_{\mathrm{BET}}$ исходных частиц $\mathrm{SiC}$. Это подтверждает тот факт, что плазмохимическая обработка частиц $\mathrm{SiC}$ позволяет получить частицы с высокоразвитой поверхностью, обусловленной ее сложным рельефом.

Таким образом, впервые был предложен плазмохимический способ модификации частиц $\mathrm{SiC}$, позволяющий получить частицы с управляемой морфологией поверхности. Было показано, что образование углеродной оболочки происходит даже в отсутствие водорода в реакторе. На основании результатов сканирующей электронной микроскопии и спектроскопии комбинационного рассеяния было установлено, что добавление 9 и 16 vol.\% водорода в реактор приводит к декорированию углеродной оболочки кремниевыми наночастицами или нитевидными нанокристаллами соответственно. Модифицированные частицы $\mathrm{SiC}$ характеризуются высокоразвитой поверхностью, их удельная площадь в 15 раз выше значения $S_{\mathrm{BET}}$ для исходных частиц $\mathrm{SiC}$. Модифицированные частицы $\mathrm{SiC}$ могут выступать в качестве наполнителя для ПКМ.

\section{Финансирование работы}

Работа выполнена в рамках государственного задания Минобрнауки России на выполнение коллективом научной лаборатории „Интеллектуальные материалы и структуры“ проекта „Разработка многофункциональных интеллектуальных материалов и структур на основе модифицированных полимерных композиционных материалов, способных функционировать в экстремальных условиях“" (номер темы FEFE-2020-0015).

\section{Благодарности}

Авторы выражают особую благодарность Красноярскому региональному центру коллективного пользования ФИЦ КНЦ СО РАН за предоставленное оборудование для обеспечения выполнения этого проекта.

\section{Конфликт интересов}

Авторы заявляют, что у них нет конфликта интересов. 


\section{Список литературы}

[1] Properties and applications of silicon carbide, ed by $\mathrm{R}$. Gerhardt (InTech, 2011).

[2] K.B. Bommegowda, N.M. Renukappa, J.S. Rajan, in Techno-societal 2020 (Springer, Cham, 2021), p. 637. DOI: 10.1007/978-3-030-69925-3_62

[3] Y. Huang, J. Hu, Y. Yao, X. Zeng, J. Sun, G. Pan, R. Sun, J.-B. Xu, C.-P. Wong, Adv. Mater. Interfaces, 4 (17), 1700446 (2017). DOI: 10.1002/admi.201700446

[4] D. Athith, P. Kittali, B. Yogesha, Mater. Today: Proc., 46 (Pt 18), 9107 (2021). DOI: 10.1016/j.matpr.2021.05.399

[5] H. Du, Zh. Ren, Y. Xu, Iran. Polymer J., 27, 621 (2018). DOI: $10.1007 / \mathrm{s} 13726-018-0638-1$

[6] H. Ma, B. Gao, M. Wang, Z. Yuan, J. Shen, J. Zhao, Y. Feng, J. Mater. Sci., 56 (2), 1064 (2021). DOI: $10.1007 / \mathrm{s} 10853-020-05279-\mathrm{x}$

[7] J. Feng, S.R. Venna, D.P. Hopkinson, Polymer, 103, 189 (2016). DOI: $10.1016 /$ j.polymer.2016.09.059

[8] Н.И. Алексеев, А.А. Кальнин, Д.Д. Карманов, В.В. Лучинин, C.А. Тарасов, Н.А. Чарыков, ЖФХ, 87 (10), 1761 (2013). [N.I. Alekseev, A.A. Kal'nin, D.D. Karmanov, V.V. Luchinin, S.A. Tarasov, N.A. Charykov, Russ. J. Phys. Chem. A, 87 (10), 1739 (2013). DOI: 10.1134/S0036024413090033].

[9] M.M. Islam, I. Abdellaoui, Ch. Moslah, T. Sakurai, M. Ksibi, S. Hamzaoui, K. Akimoto, Thin Solid Films, 654, 1 (2018). DOI: $10.1016 /$ j.tsf.2018.03.072 